Sciendo

\title{
Da Cultura da Subtileza
}

M. S. Lourenço

LanCog, Universidade de Lisboa

Disputatio Vol. 3, No. 27

November 2009

DOI: $10.2478 /$ disp-2009-0009

ISSN: 0873-626X 


\section{Da cultura da subtileza*}

M. S. Lourenço

Universidade de Lisboa

Um facto crucial no desenvolvimento da filosofia do século que agora termina foi a fragmentação da cultura filosófica europeia no que na verdade se pode considerar duas culturas filosóficas separadas, como se reflecte imediatamente na análise da literatura produzida neste século: há manifestamente uma cultura filosófica das línguas românicas (ou dos países destas línguas) cuja teoria e prática é irreconciliável com a cultura filosófica que partindo do Círculo de Viena se veio a generalizar aos países anglo-saxónicos e hoje a uma parte considerável da produção contemporânea de língua alemã. Sem querer entrar agora numa caracterização pormenorizada das diferenças que separam as duas culturas, gostaria no entanto de escolher dois critérios que facilmente isolam os aspectos vivamente antagónicos das duas culturas filosóficas, um primeiro critério de carácter cognitivo e um segundo de carácter estético ou estilístico. Assim, do ponto de vista cognitivo, a filosofia que é geralmente associada com a literatura de línguas românicas prossegue um objectivo que se pode, à falta de melhor, designar por especulativo, no sentido em que em geral se pretende à custa da associação de certas palavras ou grupos de palavras evocar pensamentos e conceitos, não sendo no entanto de todo possível provar que tal evocação é univocamente realizada pelo grupo de palavras escolhido para a representar. Em contraste, a cultura filosófica que hoje se implantou nos países anglo-saxónicos e num número crescente de universidades de língua alemã, conhecida através da designação de filosofia analítica, tem uma finalidade estritamente cognitiva, no sentido em que os seus cultores procuram através de um argumento válido demonstrar um aspecto até agora irreconhecido da estrutura do nosso conhecimento, sujeitando-se para isso a um veredicto sobre se a sua pretensão cognitiva é de aceitar ou de recusar. Os

\footnotetext{
* Segue-se cinco textos diversificados e um extracto do Prefácio de A Cultura da Subtileza, de M. S. Lourenço (Lisboa: Gradiva, 1995).
}

Disputatio, Vol. III, No. 27, November 2009 
clássicos deste modo de escrever filosofia erigiram em instrumento decisivo para o refinamento dos seus argumentos o culto da subtileza, a partir do qual também se torna possível avaliar uma teoria filosófica como interessante por ser subtil ou trivial por não ter o grau suficiente de subtileza que permita distinções conceptuais diferenciadas. E assim, passando agora para o ponto de vista estético ou estilístico, esta cultura filosófica tem que ser expressa numa prosa de recorte conceptista e não é por isso de admirar que Wittgenstein seja ao mesmo tempo um paradigma desta cultura e um artista da prosa de língua alemã deste século. Quanto à caracterização estilística da filosofia que é em geral produzida nos países de línguas românicas, ela parece ser uma reencarnação do estilo de Villemain, sobre o qual Baudelaire fez a análise definitiva no seu ensaio L'Esprit et le Style de M. Villemain:

Horreur congéniale de la clarté, dont le signe visible est son amour du style allusionnel [...] La phrase de Villemain, comme celle de tous les bavards qui ne pensent pas [...] commence par une chose, continue par plusieurs autres, et finit par une qui n'a plus de rapporte avec les précédentes que celle-ci entre elles.

O meu subtítulo «Aspectos da Filosofia Analítica» foi escolhido para sublinhar o carácter incompleto da apresentação feita da teoria e da prática da filosofia analítica, em particular nas suas relações com as subdisciplinas tradicionais da filosofia, uma incompletude que tem uma origem puramente contingente ou circunstancial. Das subdisciplinas tradicionais falta acima de tudo uma apresentação do que é o tipo de trabalho da filosofia analítica na ética, sobre o qual existe uma literatura copiosíssima e da qual se pode dizer que os seus resultados têm um grau de originalidade - e assim de subtileza — igual ao que foi atingido na filosofia da linguagem. Falta a seguir a apresentação da nova subdisciplina filosófica que se pode com direito dizer que foi uma criação da filosofia analítica em geral e de Wittgenstein em particular, nomeadamente aquilo a que ele chama filosofia da consciência e que foi fatal e erroneamente traduzida em inglês como philosophy of mind. Por último falta um relato do que tem sido o progresso feito em áreas da filosofia aplicada, como a filosofia do direito, a filosofia política e a filosofia da ciência em geral, uma designação que hoje exclui a filosofia da matemática. Chego assim propriamente ao momento da captatio benevolentiae, por meio do qual procuro arguir que a escolha apresentada é apesar de incompleta no entanto 
suficientemente representativa do espírito e da letra da filosofia analítica de modo a merecer um estudo, por parte do leitor interessado, do que diz respeito às subdisciplinas da lógica, teoria do conhecimento, estética e filosofia da linguagem.

\section{Filosofia e estética da música}

Embora as expressões «filosofia da música» e «estética da música» pareçam muitas vezes ocorrer como sinónimas, quer na linguagem corrente quer na literatura filosófica, é necessário e conveniente separar os dois conceitos, de modo a atribuir à filosofia da música o papel da construção de conjecturas acerca da natureza última da música, e à estética da música o papel de uma análise dos problemas colocados pela análise filosófica da obra de arte musical. Assim, enquanto as conjecturas avançadas pelos filósofos da música não se deixam avaliar quanto à sua correcção, as soluções propostas para os problemas estéticos suscitados pela obra de arte musical são soluções racionais (ou pelo menos racionalizáveis) e deve ser possível proceder à sua avaliação.

Enquanto a lista dos filósofos que se têm ocupado com a determinação especulativa da natureza última da música é impressionante quanto ao seu comprimento, e inclui quase todos os nomes de vulto desde Platão a Husserl, os filósofos do século XIX têm tido no entanto um eco maior do que todos os outros. Esta tendência foi certamente iniciada por Schopenhauer o qual escreveu acerca da música num livro em princípio fora do domínio da estética, e definiu a essência do pensamento musical como sendo uma expressão directa da vontade. Particularmente lisonjeiro para os filósofos foi a sua doutrina, associada àquela, de que uma tal expressão directa da vontade é capaz de representar a essência metafísica do mundo, de tal modo que a música é ela própria uma metafísica sem palavras, e assim Schopenhauer chega à conclusão anti-aristotélica de que a música é a filosofia na sua forma verdadeira. Ele foi ao ponto de construir um pequeno aforismo para a sua tese, que é uma paródia de um aforismo mais conhecido de Leibniz sobre as relações inconscientes entre o pensamento musical e o pensamento aritmético, e ao qual Schopenhauer deu a seguinte forma: «A música é um exercício inconsciente de metafísica, no qual a alma não sabe que está a fazer filosofia.» No século XIX desempenhou ainda também um papel importante a filosofia da música de Nietzs- 
che, o qual era ele próprio um músico amador, com a sua ideia de que esta é a arte dionisíaca katexokén, e ambas as filosofias serviram para a formação da Weltanschauung e da filosofia da música que se encontra na ópera e nos ensaios de Wagner, e nestes a sua dívida para com Schopenhauer é explicitamente mencionada.

Em geral pode-se dizer que os problemas da estética da música são mais acessíveis ou mais tratáveis do que as conjecturas propriamente especulativas da filosofia da música, e entre aqueles problemas há que fazer ainda uma distinção entre os que a música tem em comum com as outras artes daqueles que são específicos da obra de arte musical. Da primeira classe de problemas, daqueles que a música tem em comum com as outras artes, avulta o problema básico da representação da realidade na obra de arte musical. A primeira solução para este problema foi a de Aristóteles, segundo o qual a relação de representação é concebida como uma imitação ou mimese do objecto pela obra de arte. Sem dúvida que um proponente convicto da doutrina aristotélica consegue encontrar diversas instâncias de mimese propriamente musical, desde o galope dos cavalos de Monteverdi ao canto do rouxinol e do cuco na Sinfonia Pastoral de Beethoven ou ao ritmo do ferreiro na ópera Siegfried de Wagner: mas em breve os exemplos se esgotam e a generalidade das asserções musicais fica por esclarecer, se nos limitamos apenas ao domínio da doutrina da imitação.

Nestas circunstâncias o fundador da moderna estética da música como disciplina filosófica, Eduard Hanslick, formulou em 1854 a primeira teoria lógico-filosófica da obra de arte musical na sua obra The Beautiful in Music. Nesta obra Hanslick considera pela primeira vez as consequências que advêm para a teoria estética quando se interpreta a música como uma linguagem, para a seguir poder discutir o problema da denotação dos símbolos desta linguagem. A sua doutrina era a de que os símbolos da linguagem musical não têm denotação, e assim as únicas relações que se podem estabelecer entre eles são relações a que hoje chamaríamos sintácticas ou formais, razão pela qual a sua doutrina é justamente conhecida como formalismo musical. E disputável se no texto de Hanslick se pode acomodar ainda um esboço de semântica ou sentido para os símbolos musicais, ou se se está definitivamente perante um formalismo radical.

Por razões que não pertence agora enumerar sou a favor da primeira interpretação, sobretudo por ela proporcionar também uma base para a solução de um problema estético específico da música, que é a definição do estatuto ontológico da obra de arte musical. Uma 
formulação simples deste problema é a seguinte: partindo de um ponto de vista extensional, o estatuto ontológico da obra de arte é em geral bem definido no interior de uma ontologia de objectos, uma vez que o objecto quadro é a obra de arte pictórica, o objecto catedral a obra de arte arquitectónica, etc. O problema transforma-se em crise quando se tenta manter o ponto de vista extensional, e portanto uma ontologia de objectos, em relação à obra de arte musical. Para esta, os únicos candidatos ao estatuto de objecto são a partitura e a realização física ou sonora desta. Mas ninguém está realmente disposto a aceitar que a obra de arte musical é o conjunto das notas impressas, uma vez que estas não constituem uma experiência acústica. Mas que a obra de arte seja a realização física da partitura está sujeita à dificuldade genérica da multiplicidade de realizações possíveis. Assim a determinação do estatuto ontológico da obra de arte musical parece ser incompatível com o princípio da extensionalidade.

\section{Filosofia e introspecção cognitiva}

O que torna a nossa experiência mental surpreendente é ela ser incompreensível, outras vezes é ser ambivalente, outras vezes ainda é ser paradoxal. E assim o ponto de vista filosófico por excelência é estar surpreendido, ou estar perplexo, ou estar perante uma contradição. Em todo o caso, como a capacidade de se deixar surpreender é multiforme ou polimorfa, torna-se necessário ter uma ideia da direcção que a surpresa filosófica toma, a fim de esboçar nitidamente os seus contornos. O objectivo ou o fim da minha perplexidade filosófica é determinado pela minha vontade de eventualmente vir a ser capaz de distinguir aquilo que me aparece como sendo uma ilusão, daquilo que quero considerar ser conhecimento. Assim, o impulso que me leva a fazer perguntas, a descompreender, a querer compreender, é um impulso de conservação da minha experiência mental com vista a excluir na medida do possível a sua falsificação, não pelo mundo exterior, mas pela minha incapacidade de me separar de uma ilusão.

A filosofia tem assim um objectivo a que poderia chamar «sublime», e que consiste em distinguir o conhecimento da ilusão e, nestes termos, torna-se necessário postular a existência de uma faculdade mental capaz de fazer essa discriminação. Vou dar a essa faculdade o nome de «faculdade de introspecção cognitiva», a qual difere da introspecção usual por não ser um mero registo de dados da consciên- 
cia, mas antes a descoberta do seu significado cognitivo. O resultado do uso desta faculdade é assim um acto cognitivo, representável afinal numa expressão da nossa linguagem. O fim da introspecção cognitiva não é a produção de novos dados, mas antes a descoberta de relações interessantes entre os dados já disponíveis.

Embora me tenha exprimido sempre como se estivesse apenas no domínio da realidade psíquica, fora de qualquer juízo de valor, e falasse da introspecção cognitiva como sendo uma função neutral, como a audição ou a visão, devo dizer imediatamente que a teoria da introspecção cognitiva tem implícita um juízo de valor acerca do resultado do uso dessa faculdade, como se vê pelo facto de eu ter isolado apenas aquelas relações supostas serem interessantes.

E assim, apesar da introspecção cognitiva poder levar à descoberta de um facto, os partidários da teoria da introspecção cognitiva não gostariam no entanto de dizer que a descoberta de qualquer facto implica o uso dessa faculdade. Do mesmo modo, embora a introspecção cognitiva conduza à verdade, nem todas as verdades merecem ser consideradas o produto do uso da introspecção cognitiva. Por exemplo, é um facto e uma verdade que todos os círculos são redondos, mas não é necessário qualquer poder de introspecção cognitiva para o descobrir. Assim, o teste crucial acaba por ter lugar quando as relações interessantes, descobertas entre um conjunto de dados, deixaram de estar inconscientes e passaram a conscientes, deixaram de estar simplesmente latentes e passaram a manifestas: assim, a introspecção cognitiva é a capacidade de tornar consciente o que até aí era inconsciente e por isso desconhecido.

A palavra «resultado» é usada no vocabulário científico como sendo equivalente a um facto científico ou uma verdade, e nesse sentido não é sujeito a revisões sucessivas, tem um efeito cumulativo, no sentido em que novas verdades podem ser obtidas a partir destas e em geral obrigam, uma vez formuladas, toda a comunidade científica. Neste sentido da palavra, a filosofia não apresenta resultados. As teorias filosóficas estão constantemente sujeitas a revisão, não têm qualquer poder cumulativo e estão longe de obrigar a comunidade filosófica. Fica-se assim diante da questão de saber como é que a filosofia pode sobreviver à sua incapacidade de produzir resultados. É a filosofia de todo incapaz de produzir resultados? 


\section{Cinema, guião e jogos de linguagem}

Na percepção do filme de arte é ao fim de pouco tempo óbvio que se está diante de pelo menos duas obras de arte, a obra de arte visual constituída pela encenação e a obra de arte acústica ou literária constituída pelo guião. Nestas circunstâncias o filme de arte proporciona um analogon da experiência estética da ópera, onde também em princípio, embora nem sempre actualiter, pelo menos duas e no máximo três artes actuam simultaneamente. Esta era de resto a ideia subjacente à teoria wagneriana da ópera como Gesamtkunstwerk e é neste sentido que o filme de arte é uma realização da teoria do efeito de síntese produzido pelas artes ao realizarem a concretização da intenção poética.

De acordo com esta teoria estamos em geral perante duas situações básicas: ou o efeito de síntese é conseguido e não há lugar a uma avaliação hierárquica, ou o efeito de síntese falha e é-se forçado a distinguir valorativamente as diferentes contribuições das artes componentes para o efeito total.

Mas se esta teoria for comparada com os factos da experiência ao nosso dispor salta em primeiro lugar à vista que as situações que se encontram nas óperas Electra e Salomé, em que duas obras de arte literárias dão origem a duas obras de arte musical, constituem uma amostra irrepresentativa, e não faria por isso sentido em só a seu respeito falar de um efeito de síntese.

Em segundo lugar, o wagneriano mais fiel não consegue iludir o facto de que o libretto wagneriano não constitui uma obra de arte literária, caso em que se é forçado a reconhecer que a ópera de Wagner não consegue justamente atingir o efeito de síntese que era suposta ser capaz de exemplificar.

Nestas circunstâncias, o princípio de síntese idealizado na teoria da Gesamtkunstwerk não tem uma justificação na experiência, uma vez que enquanto em teoria as artes componentes da obra de arte total estariam subsumidas no sentido da convergência e não haveria assim lugar à definição de uma hierarquia entre elas, na prática esta convergência dá frequentemente lugar à divergência, e logo à possibilidade de as separar e avaliar hierarquicamente.

É assim surpreendente que este injustificado princípio de síntese continue a modelar os nossos hábitos mentais e a ser um dos obstáculos — mas não o único — a considerar como obras de arte autónomas algumas das artes componentes, quer na ópera, quer no filme de arte. 
É interessante por isso analisar o género de dificuldades teóricas que militam contra o reconhecimento do guião do filme de arte como obra de arte literária, um problema que é cognato dos problemas da mesma família, «Quando é que um libretto é uma obra de arte literária?» ou «Quando é que uma partitura de um filme é uma obra de arte musical?». Exemplos de soluções positivas para estes dois últimos problemas são o libretto de Hofmannsthal para a Ariadne auf Naxos de Strauss e a partitura de Hans Werner Henze para o filme de Schlöndorff Um Amor de Swann.

Em primeiro lugar é preciso definir a sintaxe do termo «guião» de modo a saber se se pode falar de guião como um género e, no caso de uma solução negativa, a que género é que o guião vai ter que pertencer.

A solução negativa recomenda-se logo na base de uma distinção entre os conceitos de forma e género, de tal modo que faça sentido dizer, como no caso do soneto, que este pertence ao género lírico mas que não constitui an sich um género, mas antes um princípio de arranjo ou um princípio estrutural, usualmente pensado como forma. Nestes termos, a denotação de «género» não é a estrutura de uma obra de arte literária mas a totalidade formada por obras de arte literárias com diversas estruturas, mas com um predicado básico comum a todas elas.

É justamente a determinação deste predicado comum que leva à construção de uma árvore dos géneros, e como este predicado não é univocamente determinável a teoria literária tem assim, em momentos diferentes, sido levada a construir árvores diferentes.

Vale a pena contrastar a mais antiga, a que provém da Poética de Aristóteles, com uma árvore frequente na teoria literária contemporânea, para documentar essa oscilação na definição dos predicados básicos. Enquanto para Aristóteles a epopeia pertence ao género poesia, um género no qual Aristóteles apenas inclui também o drama ou a poesia dramática nas suas duas formas principais, a tragédia e a comédia, na teoria literária anglo-saxónica é frequente ver a epopeia como pertencendo ao género ficção, sendo os outros géneros desta árvore o drama e a poesia. Por poesia entende-se apenas poesia lírica, uma vez que a poesia dramática nesta classificação pertence ao género drama, enquanto à ficção pertencem não só a poesia épica, mas também o romance, a novela e o conto.

Não estou a afirmar que esta classificação anglo-saxónica dos géneros tem só vantagens, mas os seus inconvenientes são no entanto menores do que os de outras classificações propostas, como a de 
Roman Jakobson, segundo a qual a definição dos predicados «lírico»e «épico» é feita apelando a uma postulada estrutura gramatical, a da primeira pessoa do singular no tempo presente e a da terceira pessoa do singular no tempo passado, respectivamente, uma estrutura que é, para mim, uma frívola ficção, uma vez que por ela ser-se-ia forçado a incluir no género épico todos os poemas líricos — são muitos — escritos na terceira pessoa do singular e no tempo passado. A este propósito seja-me permitido mencionar os adeptos do relativismo histórico, segundo os quais o conceito "género» é uma categoria literária do passado, a qual por volta do último fin de siècle deixou de fazer sentido. Mesmo concedendo a última parte do argumento, resta sempre a tarefa de definir os géneros do passado e regressam assim os problemas que se tinham tentado eliminar com o recurso ao relativismo histórico.

Um segundo momento, tão essencial como a definição dos predicados básicos é a definição da atitude a ter perante a classificação a propor. A teoria clássica do género deixa-se reconduzir a um único princípio, o da separação, o qual conduz na verdade toda a análise: na separação dos géneros quanto à pureza, na separação dos estilos, e na separação das classes sociais implicadas nos heróis da epopeia e da tragédia, até à mísera plebs da sátira e da comédia. É assim que este pathos da separação leva logo a distinguir a pureza da tragédia francesa da impureza da tragédia de Shakespeare e, acima de tudo, a exigir que a teoria do género seja de carácter prescritivo, não só por cada obra ter que pertencer a um género, mas também por esta pertença ser fixada num corpo de regras cuja execução se pode depois medir. O mesmo princípio da separação está presente na análise do estilo e na sua correlação com a origem social das personagens da obra de arte literária: o estilo alto ou elevado, que corresponde ao topo da escala social e é usado pelas personagens das tragédias e da epopeia, o estilo médio que corresponde à classe média e é característico das personagens da comédia, e o estilo baixo, associado como foi dito à sátira e à farsa.

Esta característica da separação hierárquica e regulativa da teoria clássica, presente em Aristóteles na inferiorização do poema épico perante o poema dramático, ultrapassou no século XIX as fronteiras da teoria literária e foi adoptado na estética musical sob a forma da separação da música absoluta da música de programa, em particular a concepção de que em si a sonata é uma forma mais pura do que o Lied.

Mas a experiência literária e musical nos dois últimos séculos não é conciliável com as posições da teoria clássica, e assim a concepção 
segundo a qual os géneros enquanto universais existem realiter tem que ser abandonada e substituída por uma teoria que faça justiça à experiência. Em todo o caso, a recusa deste platonismo absoluto acerca da existência objectiva dos géneros como universais não deve conduzir à sua substituição por uma forma de nominalismo igualmente irrestrito, de acordo com o qual a literatura não é mais do que o agregado de poemas, de romances e de dramas que se convenciona descrever por meio de um nome comum a todos eles.

Entre o platonismo e o nominalismo a teoria filosófica que me parece capaz de produzir uma satisfatória teoria do género é a teoria dos jogos de linguagem. Segundo esta teoria não precisamos de conceber o género apenas como um nome ou um predicado e a existência objectiva do género pode ser redefinida em termos da existência objectiva das regras do jogo de linguagem que o género constitui. Definido o género como o jogo de linguagem torna-se também possível admitir a reformulação das regras de acordo com as necessidades ou novos objectivos dos utilizadores do jogo de linguagem, neste caso de «género». Nestas condições um género não é para ser comparado a um monumento do passado mas a uma instituição viva, capaz de reforma e de redefinição. É particularmente desejável que esta capacidade de reforma seja conciliada com a existência de um núcleo invariante, uma estrutura, de modo a ser possível ainda classificar as Elegias de Duino de Rilke como um poema lírico e os Cantos de Ezra Pound como poema épico.

Uma outra vantagem da teoria dos jogos de linguagem é proporcionar uma solução para a vexata quaestio "Como é que se garante que toda a obra de arte literária pertence a um género?», em virtude do facto de os jogos de linguagem não constituírem um conjunto fechado e ser assim sempre possível estabelecer um novo género. É instrutivo pensar que problemas derivados da falácia da intenção de Wimsatt, reformulada agora em termos da intenção de produzir uma obra para um género, são igualmente resolvidos pela circunstância de a teoria dos jogos de linguagem prescindir da intenção dos utilizadores do jogo de linguagem para que este se considere constituído e, nestes termos, não é teoricamente necessário nem documentar nem descobrir a intenção de género que o autor tinha ao escrever a obra para se definir o sentido dela.

Ficamos assim com a concepção de um género como uma estrutura objectiva mas não platonisticamente imóvel, convencional sem ser nominalisticamente arbitrária. Não só o número de todos os géneros 
fica aberto como a atitude axiológica é substituída por uma atitude puramente descritiva. Não há géneros superiores e inferiores, assim como não há jogos de linguagem superiores e inferiores. O dogma da pureza do género também tem que ser abandonado, deste ponto de vista, uma vez que a confluência ou a intersecção dos jogos de linguagem é um facto da experiência, inconsistente com o princípio da separação. Resta o conjunto das regras, que fica comum às duas concepções, visto que um jogo de linguagem também tem que ser caracterizado por meio de regras.

Esta teoria é suficiente para estabelecer o guião como pertencendo ao género dramático, afastando assim a deformada concepção do guião como género. Mas uma vez esta pertença assegurada o guião partilha com todas as obras do género dramático do mesmo destino: ele só pode ser considerado uma obra de arte literária se a nossa percepção dele não depender da sua realização em filme, tal como $A t$ the Hawk's Well de Yeats é uma obra de arte literária mesmo que não seja realizada cenicamente. O facto de um realizador adoptar um guião para um filme não tem como consequência que o guião tenha deixado de existir como obra de arte literária, embora exista apenas como um fragmento da obra de arte filme. Estamos assim diante de uma situação em que o princípio de síntese da Gesamtkunstwerk é realizado com sucesso, mas ao contrário das exigências desta teoria temos agora uma síntese de duas artes autónomas, a qual é adequadamente perceptível na metáfora do contraponto a duas vozes, por vezes a cantar em uníssono, por vezes em movimento paralelo, por vezes em movimento contrário.

O cinema não produz só filmes de arte e não começou logo por ser uma arte, de modo que a teoria estética só se dirige ao fragmento da produção cinematográfica que cai debaixo do conceito de filme de arte. Estamos assim perante um complexo conjunto de relações que o filme de arte tem com as suas origens e, como vimos, com as outras artes.

\section{De novo a metafísica}

Para o senso comum as palavras «filosofia»e «metafísica» são vagamente sinónimas porque para este senso comum qualquer problema filosófico é em última análise um problema metafísico. A esta pretendida sinonímia acresce ainda o facto histórico de a metafísica ser, como a lógica, uma das disciplinas filosóficas já praticadas na Antigui- 
dade Clássica e ter tido uma função estruturadora na teoria lógica do tratado de Aristóteles intitulado Organon. No seu perfil tradicional, a metafísica é a disciplina filosófica sublime katexokén. A teoria do ser e a reflexão sobre os conceitos de substância e existência são os pontos de partida da metafísica, por meio dos quais se enfrenta as questões fundamentais da perplexidade filosófica, como «O que há no mundo?», ou «Qual é a diferença entre o ser e o nada?». A estas questões em breve se juntaram as questões sobre a natureza da alma, quer a das suas relações com o corpo quer a da sua possível imortalidade. As grandes questões sobre a causalidade, a natureza dos conceitos de espaço e tempo, eram também do domínio da metafísica, a qual incluía igualmente o tratamento racional ou argumentativo do problema da existência de Deus, em particular uma avaliação das diversas tentativas de demonstração da sua existência.

Mas o desenvolvimento da ciência moderna veio suscitar um problema óbvio de divisão de competências e passou a ser gradualmente mais difícil defender a posição de que é a metafísica quem regula o que há a saber sobre a alma, o espaço, o tempo e a causalidade. Foi exactamente esta percepção que levou o filósofo francês do século XIX Auguste Comte a formular a sua Lei dos Três Estados, segundo a qual o conhecimento humano é um progresso por fases ou estádios, sendo o conhecimento obtido na metafísica superior ao obtido nas teogonias da Antiguidade mas ainda inferior ao conhecimento científico moderno.

Enquanto na tradição filosófica de língua alemã Kant foi o primeiro a relativizar o lugar sublime da metafísica na filosofia e no pensamento em geral, os seus principais adversários encontram-se no entanto entre os filósofos do Círculo de Viena. Sem querer entrar em pormenores de carácter histórico não posso deixar de mencionar dois textos clássicos que documentam a rejeição da metafísica pelo Círculo de Viena: em primeiro lugar o «Manifesto do Círculo» e em segundo lugar o ensaio de Carnap «A Superação da Metafísica pela Análise Lógica da Linguagem». ${ }^{2}$ No seu ensaio Carnap consegue provar que a teoria clássica da dedução é capaz de mostrar como problemas corren-

\footnotetext{
${ }^{1}$ Carnap, R., Hahn, H. e Neurath, O. Wissenschaftliche Weltauffassung: Der Wiener Kreis. Wolf, Viena, 1929.

2 Carnap, R. «Überwindung der Metaphysik durch Logishe Analyse der Sprache» in Erkenntnis, Vol. II, 1932. Trad. ing. de Arthur Pap, «The Elimination of Metaphysics Through Logical Analysis of Language» in Ayer, A. J. (org.). Logical Positivism. Greenwood Press, Westport, Connecticut, 1959, 1978.
} 
tes da metafísica resultam do desconhecimento ingénuo da estrutura lógica da linguagem usada para o formular, de tal modo que uma análise desta linguagem é capaz de os revelar ou como falsos problemas ou como deduções falaciosas.

A dissolução física do Círculo de Viena e uma mudança de orientação quanto ao papel a desempenhar pela análise lógica levaram a que a metafísica recuperasse um pouco do seu prestígio mas não do seu lugar, uma vez que hoje se favorece — erroneamente ou não — uma disposição horizontal de todas as disciplinas filosóficas. O principal obstáculo à hegemonia da técnica da análise lógica na solução de problemas filosóficos foi sem dúvida criado por um interesse renovado - mais uma vez, erroneamente ou não — por aqueles aspectos da linguagem corrente que não podem ser explicados pela teoria lógica, tendo-se por isso passado a determinar o sentido de uma expressão ou de um conjunto de expressões por meio de um postulado «uso corrente», o qual é suposto agora substituir o sentido prescrito pela análise lógica. Nestas condições passa a ser possível reformular a metafísica, agora de um ponto de vista descritivo e não prescritivo. Qualquer sistema conceptual representado linguisticamente possui em estado latente um certo sistema de metafísica, um certo conjunto de ideias subconscientes acerca do ser, da alma e de Deus: a metafísica descritiva efectua, sem avaliar, uma representação desse sistema.

\section{Negação, lógica e ontologia}

Embora a inteligência humana se tenha desde muito cedo colocado diante da perplexidade que resulta do fenómeno puro da existência ou do ser, e se tenha também sem aparente sucesso posto à procura da resposta à pergunta «Porquê o ser e não o nada?», essa mesma inteligência nunca deixou de estar menos fascinada pela constatação da existência do raciocínio válido, ou da possibilidade de extrair uma consequência irrefutável a partir de uma proposição previamente dada.

Assim a inteligência humana é capaz de viver um fascínio duplo, ontológico como na pergunta pelo ser em vez do nada e lógico, como resulta do espanto pela existência da inferência válida, até no mundo mental da criança. Mas a inteligência é acima de tudo fascinada pela existência da inferência válida na vida mental do adulto, como se vê pela história da discussão em torno de paradoxos que surgem mesmo em níveis relativamente simples de conceptualização. 
Um exemplo luminoso do espanto lógico é o que nos é dado pela consideração de uma actividade mental tão simples como a negação de uma proposição dada, porque neste caso um mínimo de análise é suficiente para mostrar que por baixo desta simplicidade está uma complexidade difícil de medir e que só no nosso século, de facto, foi formulada. Logo nos primórdios da lógica, na Grécia, se descobriu que a negação de uma verdade ou a afirmação da sua falsidade pode ter consequências perturbantes.

Se eu admitir que qualquer afirmação que faço só pode ser verdadeira ou falsa, o que parece ser razoável, vejo-me logo em dificuldades para determinar qual destes valores de verdade, verdadeiro ou falso, devo atribuir a certas proposições. A frase «Tudo o que eu digo é falso» é um bom exemplo desta dificuldade. Se eu disser que ela é verdadeira, então ela é falsa, visto que tudo o que eu digo é falso; mas se eu disser que é falsa, então ela é verdadeira, por ser isso justamente o que ela afirma e logo, o que eu estou a dizer agora, é verdadeiro.

Mas a negação é ainda uma fonte de perplexidades quando aparece associada ao já mencionado conceito de existência. Se eu afirmo «O Diabo não existe» e continuando a supor que esta minha afirmação ou é verdadeira ou é falsa, sou confrontado com diversas surpresas. Se suponho que é verdadeira, então «O Diabo existe» é falsa, o que parece também ser razoável; mas se suponho que «O Diabo não existe» é falsa, então «O Diabo existe» é verdadeira. Assim a falsidade de «O Diabo não existe» parece forçar-me a aceitar a existência do Diabo.

São estas perplexidades causadas pela negação e pela existência que estão na origem da constituição das disciplinas filosóficas mais antigas, a lógica e a metafísica, nas quais precisamente o espanto lógico e o espanto ontológico são articulados sob a forma de teorias capazes de satisfazer exigências básicas de racionalidade.

A lógica como disciplina autónoma começa com a distinção entre verdade e validade, em particular com a distinção entre a verdade de uma asserção ou de um conjunto de asserções e a validade do argumento ou do raciocínio em que elas ocorrem. É válido inferir da proposição «Alguns poetas são quadrúpedes» a conclusão «Alguns quadrúpedes são poetas» embora nem a primeira proposição, chamada premissa, seja verdadeira, nem a segunda, chamada conclusão, o seja. Mas não cabe à lógica determinar que proposições são verdadeiras ou não: à lógica cabe apenas dizer que um argumento é válido se de uma premissa verdadeira não se extrai uma conclusão falsa. Assim 
a validade não é a mesma coisa do que a verdade, embora o conceito de verdade seja necessário para definir um argumento como válido.

A lógica mantém com a filosofia relações de um elevado grau de complexidade. Em primeiro lugar, como disciplina filosófica, a lógica é também uma experiência de surpresa ou de perplexidade, alguns traços das quais procurei esboçar com os meus exemplos. Mas a lógica separa-se em todo o caso da filosofia por se comportar de um modo diverso diante do teste dos resultados. Em contraste com a filosofia, a lógica constitui um corpo de resultados que não está sujeito a uma revisão constante, que tem um efeito cumulativo e que obriga toda a comunidade científica. Assim, as leis simples da inferência descobertas por Aristóteles ou as mais complexas descobertas por Frege representam uma forma de saber que não é típico na filosofia. Finalmente, põe-se a questão de saber se nestas condições é a lógica que deve determinar o curso de uma teoria filosófica ou se ao contrário é a filosofia que está na origem de uma teoria lógica.

M. S. Lourenço Universidade de Lisboa 